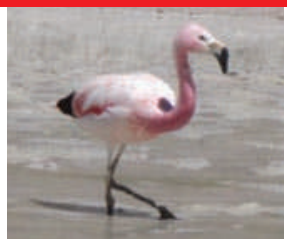

\title{
What's in a name? Fly world is abuzz
}

\section{Proposed reorganization of Drosophila fruitfly genus might throw out its most celebrated member.}

The star subject of genetic research - the Drosophila melanogaster fruitfly - may lose its name.

This is an anticipated repercussion of a decision last week by the London-based International Commission on Zoological Nomenclature. It had spent more than two years debating a petition that would have protected the hallowed name while opening the way to a major reorganization of the Drosophila genus, which includes at least 1,450 species.

The commission, which oversees the naming of all species, rejected the petition, setting the stage for a likely renaming of $D$. melanogaster and hundreds of related species. Among biologists who study various fruitfly species to link genes to traits, the 1 April ruling was no joke.

"Oh my God," says Therese Markow, a geneticist at the University of California, San Diego, who was reached in the Sonoran Desert, where she was collecting fruitflies. Markow, who is director of the university's Drosophila Species Stock Center, added that extensive name changes could "wreak havoc" in the Drosophila literature and databases.

The naming debate began when a US scientist filed a petition with the commission to designate D. melanogaster as the Drosophila type species - the accepted standard of the genus (see Nature 457, 368; 2009). Kim van der Linde, an ecologist at Florida State University in Tallahassee, wanted to ensure that the name $D$. melanogaster would not change if the genus were divided, as she and other scientists advocate. The genus is extremely large, and genetic data suggest that some of its member species are more closely related to flies outside the genus than they are to other Drosophila species.

In the end, the commission voted 23 to 4 to reject van der Linde's petition. The designated type species will continue to be Drosophila funebris, described in 1787 by Johann Fabricius. But the proposal forced the taxonomic world to face the possibility that the genus in its present form may be untenable.

In their written opinions, commission members gave several reasons for voting against the new proposal. Many called it premature because the science about the organization of the Drosophila genus remains unsettled. Others sought to limit the naming disruptions that would occur if the genus were split. Drosophila melanogaster fits within a subgenus called Sophophora, which includes some 350 members. Splitting this group off to form a new genus would require fewer renamings than would be needed if $D$. melanogaster became the type species for Drosophila. In that case, roughly 1,100 species would be pushed off into new genera.

"It was very difficult for the commissioners," says Ellinor Michel, the commission's executive secretary. "It was a question of celebrity, as everyone knows

\section{D. melanogaster."}

If a researcher were to use current data to publish a revision of the Drosophila genus, D. melanogaster would probably become Sophophora melanogaster. Van der Linde says that if she and her co-authors from the petition can agree, they may present the case for the change. "Something needs to happen," she says.

But even if the celebrity fly is renamed, Michel noted, it may still be referred to by its original name.

Rex Dalton

\section{Animals thrive without oxygen at sea bottom}

Living exclusively oxygen-free was thought to be a lifestyle open only to viruses and single-celled microorganisms. A group of Italian and Danish researchers has now found three species of multicellular animal, or metazoan, that apparently spend their entire lives in oxygen-starved waters in a basin at the bottom of the Mediterranean Sea.

The discovery "opens a whole new realm to metazoans that we thought

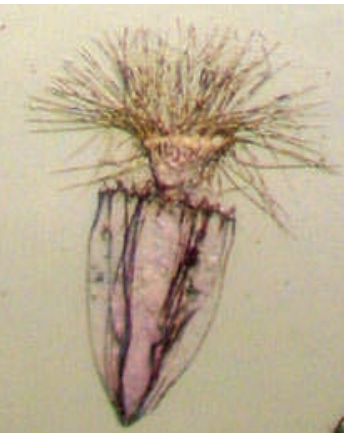

Some loriciferans live in anoxic sediments. was off limits", says Lisa Levin, a biological oceanographer at Scripps Institution of Oceanography in La Jolla, California.

Roberto Danovaro from the Polytechnic University of Marche in Ancona, Italy, and his colleagues pulled up the animals during three research cruises off the south coast of Greece. The species, which have not yet been named, belong to a phylum of tiny bottom-dwellers called Loricifera. Measuring less than 1 millimetre long, they live at a depth of more than 3,000 metres in the anoxic sediments of the Atalante basin, a place so little explored that Danovaro likens his team's sampling to "going to the Moon to collect rocks".

Researchers have previously found multicellular animals living in anoxic environments, but Danovaro says that it was never clear whether those animals were permanent residents. The new loriciferans, which he and his team reported this week (R. Danovaro et al. BMC Biol. doi:10.1186/1741-7007-8-30; 2010), seem to "reproduce and live all their life in anoxic conditions", he says.

The researchers identified an adaptation that helps these loriciferans to survive in their environment. Instead of mitochondria, which rely on oxygen, the creatures have organelles that resemble hydrogenosomes, which some single-celled organisms use to produce energy-storing molecules anaerobically.

Angelika Brandt, a deep-sea biologist at Germany's Zoological Museum in Hamburg, says that the work by Danovaro's group is "highly significant". The discovery of metazoans living without mitochondria and oxygen, she says, suggests that animals can occupy niches that once seemed too extreme.

Janet Fang

Correction
The News Feature 'The human race' (Nature
$\mathbf{4 6 4 , 6 6 8 - 6 6 9 ; 2 0 1 0 ) ~ m i s s p e l t ~ t h e ~ n a m e ~ o f ~ t h e ~}$
architect of whole-genome shotgun sequencing.
It should be Gene Myers. This error has been
corrected online in the HTML and PDF versions
of this story.

\section{Correction}

The News Feature 'The human race' (Nature architect of whole-genome shotgun sequencing. of this story. 